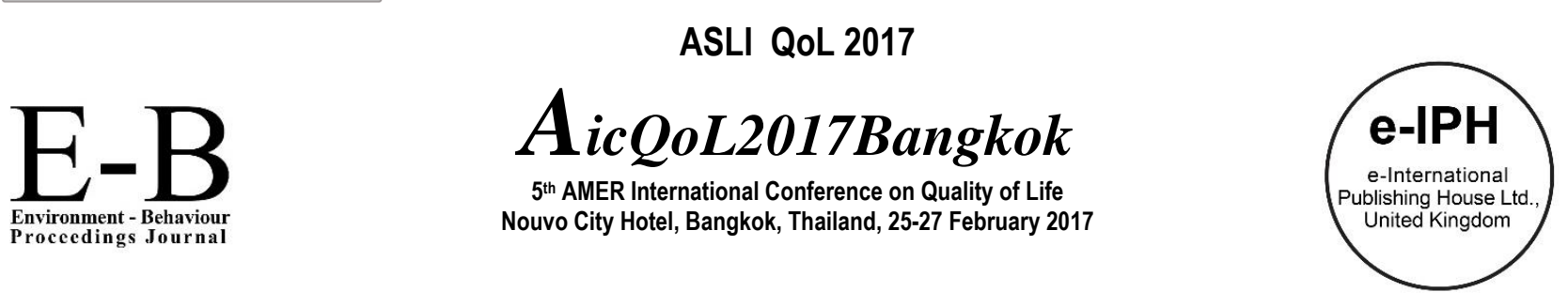

\title{
Attitude towards Safe Driving Scale (ASDS-46) as a Future Predictor in Determining a Young Adult Quality Of Life: Part II
}

\author{
Mohamad Ghazali Masuri ${ }^{* *}$, Akehsan Dahlan¹, Ajau Danis², Khairil Anuar Md Isa² \\ ${ }^{1}$ Occupational Therapy Department, Faculty of Health Sciences, UiTM Puncak Alam Campus, Selangor, Malaysia \\ ${ }^{2}$ Basic Sciences Department, Faculty of Health Sciences, UiTM Puncak Alam Campus, Selangor, Malaysia
}

\begin{abstract}
The purpose of part II is to explain the correlation between driver's attitude and their quality of life. Based on the previous study, Attitude towards Safe Driving Scale (ASDS-46) was used jointly with and WHOQOL-BREF to examine the relationship. The result showed that ASDS-46 and WHOQOL-BREF have a high level of reliability with Cronbach's Alpha value .887 and .853 respectively. Domain 2 and 3 (psychological \& social relationship) shows a positive correlation with the value of ( $P=.003$ and .017$)$. This study concludes that the positive correlation between driver's attitude and the psychological domain is an alarming issue which needs further investigation.
\end{abstract}

Keywords:ASDS-46; WHOQOL-BREF; driver's attitude; young adult

(c) 2017.The Authors. Published for AMER ABRA by e-International Publishing House, Ltd., UK. This is an open access article under the CC BYNC-ND license (http://creativecommons.org/licenses/by-nc-nd/4.0/). Peer-review under responsibility of AMER (Association of Malaysian Environment-Behaviour Researchers), ABRA (Association of Behavioural Researchers on Asians) and cE-Bs (Centre for Environment-Behaviour Studies), Faculty of Architecture, Planning \& Surveying, UniversitiTeknologi MARA, Malaysia.

\subsection{Introduction}

The main function of road transport system is to help and improve people mobility from one place to another. However, this system comes with a significant risk. Ministry of Works, Malaysia highlights four approaches in their Road Safety Program. To improve the road safety, the following engineering approaches are utilized: accident preventions (proactive action), accident reduction (reactive action), road maintenance and building new roads (Mustafa, 2006). Promoting efficient patterns of land use, improving public transportation systems by providing less exposure and safe route to susceptible road users can help to eliminate the road accident (Worley, 2006). Road crashes cause death and disabilities which contributes to significant financial and psychological burden to our society. This public threat perhaps will increase public awareness where RTA is a serious public issue, and at the same time, it is a global public health burden. This phenomenon shows a very clear picture where human behavior plays major roles in contributing to a road accident. Accident and injuries will usually contribute to significant burden to our society and reduce their quality of life (QoL). It is suggested that behavior is the primary concern in planning intervention strategy where it can be prevented through behavior change (Prentice-Dunn, 2004). The question is how many people are aware of this risk? How many people are aware that the threats are severe? According to Weinstein, Lyon, Sandman, \& Cuite the most crucial stage in prevention strategy is to make people pay attention, become aware and take serious steps toward a risk (1998).

Driving play an important role in our life as people travel from one place to another place by using several mode transportations such as personal or public transportation. This makes traveling become a very important aspect in the quality of life (QOL). As an occupational therapist, we were involved in educating, promote, evaluate, modify and rehabilitate people to become an Independence individual since driving can be part of the important component in the occupational performance area. This topic is relevant to the occupational therapist with regards to the profession itself as a health prevention, health promotion, and health education. This study was conducted among UiTM Puncak Alam students population, and the results will be able to explain the perception of educated young adult drivers in Puncak Alam towards speeding and associated risk. The results could be used to provide information to the targeted population regarding the issues. Hence appropriate intervention and strategies can be planed to reduce the road crashes.

\footnotetext{
* Corresponding author. Tel.: +6019-6259314

E-mail address: zalie222@gmail.com
}

(C) 2017. The Authors. Published for AMER ABRA by e-International Publishing House, Ltd., UK. This is an open access article under the CC BYNC-ND license (http://creativecommons.org/licenses/by-nc-nd/4.0/). Peer-review under responsibility of AMER (Association of Malaysian Environment-Behaviour Researchers), ABRA (Association of Behavioural Researchers on Asians) and cE-Bs (Centre for Environment-Behaviour Studies), Faculty of Architecture, Planning \& Surveying, UniversitiTeknologi MARA, Malaysia.

DOI: http://dx.doi.org/10.21834/e-bpj.v2i5.705 
Thus, from this study, the outcomes of this study will give benefits to the people and country so that the accidents rate can be decreased and save more life. RTA will give a huge impact to the individual and communities that include socio life, economic and also may cause damage to the property. The impact of the road traffic accident to the person may be fatal or non-fatal injuries that may lead to disability. Road traffic accident will cause a lost to country due to the government need to spend the money for the cost of treatment and rehabilitation for the injured person. Therefore, a proactive measure needs to take account to reduce the rate of road traffic accident. This present study will identify the prevalence use of text messaging while driving among young adults and their risk perception towards that's behavior. Road traffic accident has become a great issue and health problem in worldwide. Currently ranked eight, it has been estimated that by 2030 road traffic accident will become the fifth leading cause of death in the world. According to World Health Organization, (2007), over 1.2 million people die annually on the world's road and between 20 and 50 million sustain non-fatal injuries due to road traffic crash. Based on research conducted by the University of Michigan, "Malaysia was ranked as the top of 25 most dangerous countries in the world road accident", with estimated that 30 fatalities per 100,000 individual. Besides, the number of the road accident and fatalities are an increase compared with last year in 2014 with 1557 people involve in the road accident, and 1696 were killed (Royal Malaysian Police, 2007). This high number of the road accident is quite worrying as this death and injury will give the negative impact on the family, community and also the country. These numbers of injuries keep arising every year and had become a frightening issue in health and may contribute to significant effect on people quality of life (Wan Ahmad Kamal, Masuri, Dahlan, \& Md Isa, 2015).

RTA frequently involves multi-level society, and this has become a demanding community issue where more serious participation is needed to improve driver's attitude in the future. RTA has a significant impact on quality of life and financial burden to the government and Malaysian society. The number of road traffic accidents among young adult is an alarming issue in Malaysia. Malaysian governments through relevant agencies have worked very hard to enforce all relevance acts related to it. One of the prime government objectives is to ensure safer Malaysian drivers in the future. To date, there were still a limited number of local research and evidence supporting the elements of driver's attitudes and behavior analysis had been conducted.

Driving is one of the most critical activities of daily living that involves the active eye, hand, and foot coordination. Drivers that is not proficient or fail to organize and interact with their vehicle and surrounding environment may lead to road traffic injury (RTI) (Masuri, Md Isa, \& Mohd Tahir, 2012). This interaction could play a major role in preventing and predicting future studies. The majority of road traffic accidents were caused by human error. This made the drivers' error as an important human component that needs to be further investigated. These road injuries and fatalities have become a great concern for the Malaysian government. This scenario may be due to rapid development in Malaysia (Mohamad Ghazali Masuri, Akehsan Dahlan, Ajau Danis, \& Khairil Anuar Md Isa, 2015a). This rapid development contributed to the increasing number of vehicle on the road that could potentially increase the possibilities of RTA. There were many causes of an accident either it is due to primary or secondary factors. Factors such as speeding, using a mobile phone and not wearing a seat belt are considered as a contributing factor for injury and fatality (Md Isa et al., 2012).

Many studies have proven that attitudes rarely present the synchronize behavior. Attitudes can be presented either in a positive or negative form. Even though attitude and behavior were not usually straightforward, and they are sensitive according to the social situation, but, attitude assessment can be used to predict future behavior (Iversen, 2004). Understanding of human attitudes relates to driving behaviors were very critical to developing more appropriate planning and intervention in reducing the prevalence of RTA. At present, there was limited evidence available to justify which human components were needed to be addressed. Previous study shows that, different factors such as socio-demographic issues (Al-Naggar, Bobryshev, \& Mohd Noor, 2013), socioeconomic status (Masuri, Md Isa, \& Mohd Tahir, 2012), age/gender (Scott-Parker, Watson, King, \& Hyde, 2012), education level (Masuri et al., 2012) and living status (Al-Naggar et al., 2013) brought significant effects on driving behaviour. Speeding behavior among young adult in Malaysia frequently involves stimulation from our society. This behavior has become a demanding community issue where more serious community participation is needed to improve the future of young drivers. It is important to understand that, the stimulation that involves which contributed to risk-taking behavior among young drivers is usually beyond our control. It was a little unfair to depend solely only on the government to improve the drivers' behavior and their quality of life. Public participation such as parents, teachers and the most important thing; participants circle of friends, is to a large extent were needed in shaping a better future in the road and transportation system in Malaysia. A deeper understanding of the young drivers' behavior is needed to enhance the plan for preventive measures. For example the study on the differences of the belief among the high and low intender to speed by (Forward, 2009) and (Horvath, Lewis, \& Watson, 2012). Similarly, a study finding on the belief influencing drivers' hands-free and hand-held mobile phone use (White, Hyde, Walsh, \& Watson, 2010; Zhou, Wu, Patrick Rau, \& Zhang, 2009). Such study finding can guide more relevant road safety solutions to encourage the safer road user behavior, especially among the young adult nowadays. In future, to understand this situation, we must gain a deeper understanding of the beliefs underlying behind the driver's intention to speed for both genders. The finding of this study also suggested the intention speed was caused by the pressure from the peer (or familiar person). By promoting safe behavior on the road for changing the views of the driver, it was predicted to have the capability to prevent RTA. Also, the result of this study could provide a good insight into the government, related agencies, and mass media to promote better road safety in future. Moreover, the other implication of this research was it can help Government to plan a more cost-effective campaign. The slogan such 'first class facility, this class mentality' should be changed to suit the status of developing the country by the year 2020. This evaluation could be used in screening and re-evaluation process of licensing in Malaysia. This evaluation also will be able to help the government in producing a better road society in the future. In summary, the current study concluded that correct stimulation while driving could help drivers to change their intention to speed. This behavior changes is important where it will be able to reduce the potential for accident (Masuri, Abang Mustaffa, Dahlan, \& Md. Isa, 2016) and has an indirect effect on saves people life and increase the quality of life. According to (Scott-Parker et al., 2012), individual aged 25 years old and below were considered as young drivers that frequently 
novices that are new to the driving experiences. A previous study had reported the percentage of young adult driver age between 17 and 24 commit traffic violations. The age group of the driver that strongly support the traffic violation countermeasure and moderate view toward traffic rule compliance was an older driver that aged 65+ (Vardaki \& Yannis, 2013). Speed over the limit was found to be one of the major causes of this accident. With regards to speeding behavior, there were many human components that usually become significant variables that need to be investigated. It created a lot of debates among society. However, there has been limited to work on this issue in Malaysia.

In committing road violation, the previous study showed strong evidence that one of the factors contributing off the violence action were influences from a lot of internal and external stimulus including their sociodemographic characteristics. For example, some studies had claimed that novice drivers demonstrate higher risky driving behavior compared to an older driver, and they were also found to be the highest number that involves with road crashes. Therefore, these phenomena could be used as a reference in developing intervention about safety awareness and road safety campaign among young adult. For the last few years, a group of researcher under traffic accident and cognitive ergonomics (TRACE) from Faculty of Health Sciences, Universiti Teknologi MARA, has extensively conducted research among educated young adult in understanding their driving attitude and the risky driving behavior. The main objective of TRACE is to develop a deep understanding of driver's behavior, cognitive respond and their relations towards the quality of life. The main outcome of these four years of extensive research is the invention of the ASDS-46 questionnaire. This paper is an extension of part I which was successfully presented at AicQoL2016Medan; (Masuri, Dahlan, Danis, \& Isa, 2016). The purpose of this second part is to explain the correlation between driver's attitude and their relationship with quality of life. Based on the previous study, Attitude towards Safe Driving Scale (ASDS-46) was used jointly with and WHOQOL-BREF to examine the relationship.

\subsection{Method}

This study was specifically focusing on the young adult from all over Malaysia which had multiple socio-demographic backgrounds. A cross-sectional study was conducted among Malay undergraduate university students from all over Malaysia. Each respondent was asked to fill in four pages of the ASDS-46 questionnaire and two pages of WHOQOL-BREF at the same time. Both questionnaires were used to measure their driving attitude and quality of life according to six and four important domains of the assessments. The questionnaire consists of two sections. Section 1 of the questionnaire consists of 22 demographic data that should be fulfilled by the respondent. The demographic data includes gender, age, faculty, and course, the level of education, driving licensed held (month), type of licensed, lifetime mileage, average minutes driving per week, frequency involves in a traffic accident and the rate of participation in speeding behavior for the past three months. Section 2 of the questionnaire contains 46 questions. These 46 items cover all of the main and sub-themes that were discovered during previous research. Before research implementation, the ethical clearance was gathered from Faculty of Health Science and Committee Research Centre (CRC), Universiti Teknologi Mara.

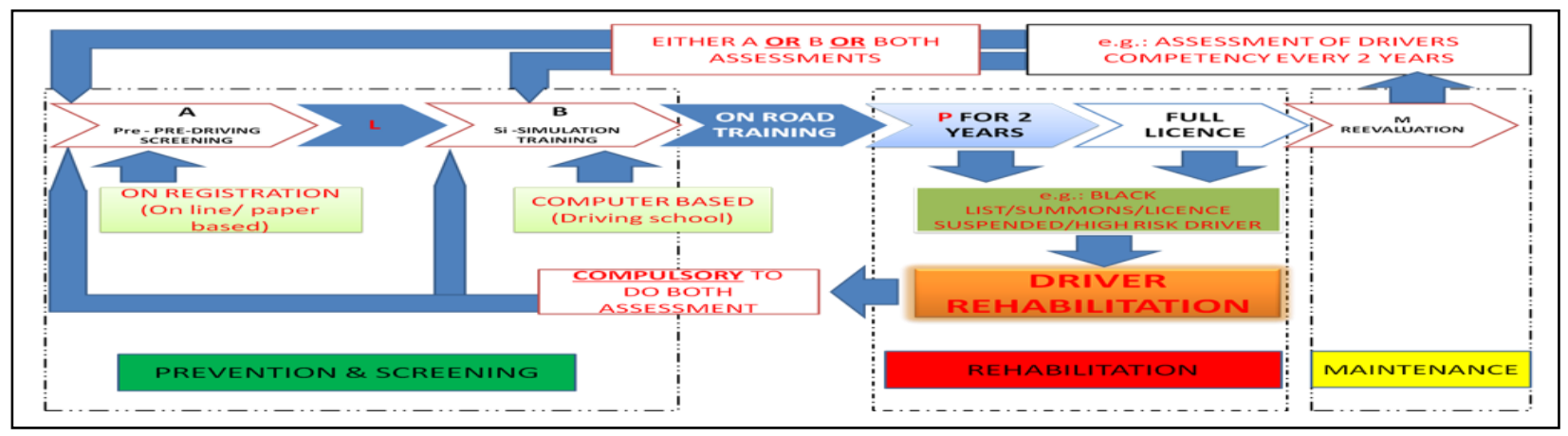

Fig. 1: PreSiM model (Mohamad Ghazali Masuri, Akehsan Dahlan, Ajau Danis, \& Khairil Anuar Md Isa, 2015b)

The research model that has been used was based on PreSim model by (Masuri et al., 2015b). PreSiM (Fig. 1) has successfully highlighted the important of pre-assessment, monitoring and maintenance of the licensing process. It was also recommend introducing reassessment and rehabilitation as part of the maintenance process. Maintenance phase may be very significant to be able to change driver's behavior, yet good screening method and law enforcement will shape better drivers in the future. All respondent have agreed that driver's behavior is the major causes of RTA in Malaysia. They also suggested that drivers competency should be reassessed in the future. Since the entire respondent already has a driving license, the survey conducted will fall under the 'maintenance' phase. The WHOQOL-BREF questionnaire was also distributed together with ASDS-46. All respondent were required to answer the entire questions.

\subsection{Results}

A total of 150 questionnaires were distributed, and only 139 (93\%) participants had returned the complete the questionnaire. A total of 139 (20.9\%) male and 110 (79.1\%) female, young novice driver from Universiti Teknologi Mara, Kampus Puncak Alam had voluntarily taken part in this study. Most of the participation aged range from 20-21 (69.1\%) years old and holding open licensed (held licensed 
more than two years). The result showed that ASDS-46 and WHOQOL-BREF have a high level of reliability with Cronbach's Alpha value .887 and .853 respectively. Table 1 shows the details of participants demographic data (Gender, age, area of living, types of traffic offenses, driving licensed held, mileage per year and history of involved in an accident).

Table 1. Demographic data

\begin{tabular}{ll}
\hline Characteristic (N=139) & Frequency (percentage) \\
\hline Gender & $29(20.9)$ \\
Male & $110(79.1)$ \\
Female & \\
\hline Age & $96(69.1)$ \\
$20-21$ & $43(30.9)$ \\
22-24 & \\
\hline Area of living & $61(43.9)$ \\
Urban & $65(46.8)$ \\
Rural & $13(9.4)$ \\
Others & \\
\hline RTA offences (Yes answer) & $52(37.4)$ \\
Speeding & $58(41.7)$ \\
Against red light & $51(36.7)$ \\
Safety belt & $49(35.3)$ \\
Mobile phone & $50(36.0)$ \\
Carelessness & $24(17.3)$ \\
Double line & $15(10.8)$ \\
Overtaking queue & $20(14.4)$ \\
Signaling & $5(3.6)$ \\
Emergency lane & $7(5.0)$ \\
No respect to other drivers & \\
\hline Driving licensed held (months) & $57(41.0)$ \\
1-24 & $69(49.6)$ \\
25-60 & $6(4.3)$ \\
61-96 & $1(0.7)$ \\
97-120 & $6(4.3)$ \\
Others & $103(74.1)$ \\
\hline Lifetime mileage (km per year) & $33(23.7)$ \\
<10,000 & $2(1.4)$ \\
10,000-30,000 & $1(0.7)$ \\
>30,000 & $110(79.1)$ \\
Others & $29(20.9)$ \\
\hline Involve in traffic accident & \\
None & $82(59.0)$ \\
Yes & $57(41.0)$ \\
\hline Witness in traffic accident & \\
None & \\
Yes & \\
\hline & \\
& \\
\hline
\end{tabular}

Near half of the respondent, $43.9 \%(n=61)$ were living in the urban area followed by $46.8 \%(n=65)$ in rural and thirteen $(9.4 \%)$ of the respondent unable to identify their area of living. With regards to road traffic offenses, nearly half of the respondent claims that they had involved with speeding and against the red light, $37.4 \%$ and $41.7 \%$. The third highest offenses that had been claimed by the respondent is not wearing safety belt followed by using a mobile phone, $36.7 \%$ and $35.3 \%$ respectively. The other common traffic offenses were, careless while driving (36\%), overtaking at the double line $(17.3 \%)$, overtaking queue $(10.8 \%)$, poor signaling (14.4\%) and use an emergency lane (3.6\%). Surprisingly, there were seven respondents (5\%) of the respondent claims that they have a lack of respect to other road users. More than one-fifth of the respondent, $41 \%(n=57)$, has a probational $(P)$ license and majority of the respondent, $59 \%$, $(n=82)$ held a full license. Most of the respondent, $74.1 \%(n=103)$, had traveled around 10,000km per year, and only 36 respondent claimed that they had traveled more than $10,000 \mathrm{~km}$ per year. Forty-one percent $(n=57)$ of the respondent had witnessed an accident yet only $20.9 \%(n=29)$ had involved with road traffic accident.

Table 2 (a) and (b) shows the total score of ASDS-46 domains (facets not included) including the mean, minimum and maximum score for each domain categories. The mean score for all six domains of ASDS-46 and raw score for all four domains of WHOQOLBREF was as follows: $(43.8,44.4,21.1,21.3,12.8,13.8$ and mean total score; 164.8) followed by $(23.2,20.9,10.1$ and 28.6$)$ respectively.

Table 2. (a) ASDS-46 score for each domains (D1: self compliant; D2: self-confidence; D3: self-benefit; D4: self-concern; D5: driving style; D6: selfpreparedness) (b) WHOQOL-BREF score for each domains (D1: physical health; D2: psychological; D3: social relationship; D4: environment)

\begin{tabular}{lllllll}
\hline ASDS-46 domain & D1 & D2 & D3 & D4 & D5 & D6 \\
\hline Mean & 43.81 & 44.35 & 21.06 & 21.26 & 12.82 & 13.78 \\
Median & 43.00 & 44.00 & 21.00 & 21.00 & 13.00 & 14.00 \\
Mode & 38.00 & 43.00 & 18.00 & 20.00 & 13.00 & 12.00 \\
Std. Deviation & 10.31 & 6.12 & 4.14 & 2.79 & 2.74 & 164.00 \\
Minimum & 13.00 & 28.00 & 9.00 & 13.00 & 4.00 & 157.00 \\
Maximum & 65.00 & 60.00 & 30.00 & 25.00 & 20.00 & 17.04 \\
\end{tabular}


The minimum and maximum raw score for each domain of WHOQOL-BREF were as follows: D1: 7-35; D2: 6-30; D3: 3-15; D4: 840. Those raw scores will later be converted into a transform scores. There were two types of transform scores available i) 4-20 and ii) $0-100$.

\begin{tabular}{lllll}
\hline WHOQOL-BREF domain & D1 & D2 & D3 & D4 \\
\hline Mean & 23.22 & 20.86 & 10.06 & 28.56 \\
Median & 23.00 & 21.00 & 10.00 & 28.00 \\
Mode & 23.00 & 21.00 & 11.00 & 32.00 \\
Std. Deviation & 3.02 & 2.51 & 1.92 & 4.49 \\
Minimum & 16.00 & 13.00 & 5.00 & 20.00 \\
Maximum & 31.00 & 27.00 & 14.00 & 54.00 \\
Sum & 3227.00 & 2899.00 & 1398.00 & 3970.00 \\
\hline
\end{tabular}

Table 3 shows the correlation between ASDS-46 domain and WHOQOL-BREF domain score. For the purpose of this analysis, a method of converting raw scores from Table 2 (b) was transformed into 4-20 scale.

Table 3. Correlation table between ASDS-46 domains and WHOQOL-BREF domains

\begin{tabular}{|c|c|c|c|c|c|c|}
\hline \multicolumn{7}{|c|}{ ASDS-46 domains. } \\
\hline WHOQOL-BREF domains & D1: self-compliant & D2: self-confidence & D3: self-benefit & D4: self-concern & D5: driving style & $\begin{array}{c}\text { D6: self- } \\
\text { preparedness }\end{array}$ \\
\hline Domain 1: Physical health & $-0.217^{*}$ & $0.190^{*}$ & 0.009 & $-0.172^{*}$ & $0.167^{*}$ & 0.005 \\
\hline Domain 2: Psychological & 0.036 & $0.286^{* *}$ & $0.268^{* *}$ & 0.075 & -0.031 & -0.700 \\
\hline Domain 3: Social relationships & -0.095 & $0.248^{* *}$ & $0.302^{* *}$ & 0.027 & -0.013 & 0.033 \\
\hline Domain 4: Environment & $-0.203^{*}$ & 0.128 & 0.109 & $-0.211^{*}$ & -0.007 & 0.052 \\
\hline
\end{tabular}

Table 3 presents the correlation table for the six domains of the ASDS-46 (D1-D6) and four domains of WHOQOL-BREF (Domain 1-Domain4). This table was calculated to test the null hypothesis of no association between two variables. According to Table 3, most of the items are significantly correlated each other. All significant correlations are labeled in bold. The evaluation showed that the correlation for each domain ranges from -0.211 to 0.302 . This table showed low correlation with some and moderate correlation with others, suggesting several factors available in this scale. Domain 1 was correlated with the most number of ASDS-46 domains except D3 and D6. Psychological and social relationship domains found to be positively correlate with D2 and D3 of ASDS-46. However, domain environment had negatively correlated with D1 and D4. Domain 2, 3 and four were correlated to D1 to D4, except D6. Interestingly, all WHOQOL-BREF does not correlate with D6 of ASDS-46. The largest significant correlation value was observed between D3 and Domain $3(p=0.302)$, whereas the lowest correlation value estimated was observed between D4 and Domain $4(p=-0.211)$. There was a positive correlation reported between total score of ASDS-46 and domain 2 (psychological) of WHOQOL-BREF (Pearson=.183, $\mathrm{P}=.031$ ). There was no correlation identified between the male total score of ASDS-46 with all WHOQOL-BREF domains. However, domain 2 and 3 (psychological \& social relationship) shows the positive correlation with the value of $(P=.003$ and .017$)$.

\subsection{Conclusion}

This study concludes that the positive correlation between driver's attitude and the psychological domain is an alarming issue which needs further investigation. This study would also hypothesize that high level of psychological components contributes to positive driver's behavior yet, the need for further analysis. The issue related to the quality of life should be looked from varieties of an angel, and driving attitudes are one of the indicators which seem to be promising to look into. Therefore, plan for rehabilitation program and improvement safe driving practice should use a holistic approach and also take into account their current quality of life status.

\section{Acknowledgements}

The highest appreciation goes to the Ministry of Higher Education Malaysia (MoHE), Royal Malaysia Police, SPAD, PROTON Professor office, Research Management Centre (RMC) Universiti Teknologi MARA (UiTM), CoRe Management Science, OPERA RIG, and all staff of the Faculty of Health Sciences UiTM Puncak Alam for continuous support in staff research and development. Thank you to our strategic partner, Majlis Bandaraya Petaling Jaya (MBPJ), and our future local and international collaborators: Universiti Malaysia Kelantan (UMK), Universiti Kuala Lumpur (UNiKL), Institut Teknologi Bandung (ITB), Asan City Council Republic of Korea, Bandung City Government, Indonesia, Qingyuan City Council, Guangdong Republic People of China and Seongbuk-gu City Council, Republic of Korea. Lastly, specially mentioned to our beloved friend and research team; Allahyarham Anniz Fazli Ibrahim Bajunid. This study was funded under Fundamental Research Grant Scheme (FRGS) by MoHE - (600-RMI/FRGS 5/3 (118/2013). 


\section{References}

Al-Naggar, R. A., Bobryshev, Y. V., \& Mohd Noor, N. A. B. (2013). Lifestyle practice among Malaysian university students. Asian Pacific journal of cancer prevention, 14(3), 1895-1903.

Forward, S. E. (2009). The theory of planned behaviour: The role of descriptive norms and past behaviour in the prediction of drivers' intentions to violate. Transportation Research Part F: Traffic Psychology and Behaviour, 12(3), 198-207. doi:http://dx.doi.org/10.1016/j.trf.2008.12.002

Horvath, C., Lewis, I., \& Watson, B. (2012). The beliefs which motivate young male and female drivers to speed: A comparison of low and high intenders. Accident Analysis \& Prevention, 45(0), 334-341. doi:http://dx.doi.org/10.1016/j.aap.2011.07.023

Iversen, H. (2004). Risk-taking attitudes and risky driving behaviour. Transportation Research Part F: Traffic Psychology and Behaviour, 7(3), $135-150$. doi:http://dx.doi.org/10.1016/j.trf.2003.11.003

Masuri, M. G., Abang Mustaffa, D. N., Dahlan, A., \& Md. Isa, K. A. (2016). The Intention in Speeding Behavior between Low and High Intended Young Driver in Urban University. Environment Behaviour Proceedings Journal, 1(1), 330-335.

Masuri, M. G., Dahlan, A., Danis, A., \& Isa, K. A. M. (2016). Attitude towards Safe Driving Scale (ASDS) As a Future Predictor in Determining a Young Adult Quality Of Life: Part I. Procedia - Social and Behavioral Sciences, 234, 390-397. doi:http://dx.doi.org/10.1016/j.sbspro.2016.10.256

Masuri, M. G., Dahlan, A., Danis, A., \& Md Isa, K. A. (2015a). Public Participation in Shaping Better Road Users in Malaysia. Procedia - Social and Behavioral Sciences, 168(0), 341-348.

Masuri, M. G., Dahlan, A., Danis, A., \& Md Isa, K. A. (2015b). Regeneration of Road System in the Urban Environment: Will Rehabilitation Components Orientate Road Users? Procedia - Social and Behavioral Sciences, 170(0), 700-708. doi:http://dx.doi.org/10.1016/j.sbspro.2015.01.072

Masuri, M. G., Md Isa, K. A., \& Mohd Tahir, M. P. (2012). Children, Youth and Road Environment: Road Traffic Accident. Procedia - Social and Behavioral Sciences, $38(0), 213-218$

Md Isa, K. A., Masuri, M. G., Abd Aziz, N. A., Md Isa, N. N., Hazali, N., Mohd Tahir, M. P., ... Hassan, H. F. (2012). Mobile Phone Usage Behaviour while Driving among Educated Young Adults in the Urban University. Procedia - Social and Behavioral Sciences, 36(0), 414-420.

Mustafa, M. N. (2006). Overview of current road safety situation in Malaysia. Retrieved from http://www.unescap.org/ttdw/common/TIS/AH/files/egm06/roadsafety_malaysia.pdf

Prentice-Dunn, S. (2004). Protection Motivation Theory and Skin Cancer Risk: The Role of Individual Differences in Responses to Persuasive Appeals Retrieved 11.10.2007 http://www.acrwebsite.org/topic.asp?artid=285.

Royal Malaysian Police. (2007). Road traffic accident and fatality statistics. Retrieved from http://www.rmp.gov.my/

Scott-Parker, B., Watson, B., King, M. J., \& Hyde, M. K. (2012). Confirmatory factor analysis of the Behaviour of Young Novice Drivers Scale (BYNDS). Accident Analysis \& Prevention, 49(0), 385-391. doi:http://dx.doi.org/10.1016/j.aap.2012.02.021

Vardaki, S., \& Yannis, G. (2013). Investigating the self-reported behavior of drivers and their attitudes to traffic violations. Journal of Safety Research, 46(0), 1-11. doi:http://dx.doi.org/10.1016/j.jsr.2013.03.001

Wan Ahmad Kamal, W. N. H., Masuri, M. G., Dahlan, A., \& Md Isa, K. A. (2015). Seat Belt Compliance and Quality of Life among Educated Young Adults in an Urban University. Procedia - Social and Behavioral Sciences, 202, 442-447. doi:http://dx.doi.org/10.1016/j.sbspro.2015.08.249

Weinstein, N. D., Lyon, J.E., Sandman, P.M., \& Cuite, C.L. . (1998). Experimental evidence for stages of health behavior change: the precaution adoption process model applied to Home Radon testing. Health Psychology, 17(5), 9.

White, K. M., Hyde, M. K., Walsh, S. P., \& Watson, B. (2010). Mobile phone use while driving: An investigation of the beliefs influencing drivers' hands-free and handheld mobile phone use. Transportation Research Part F: Traffic Psychology and Behaviour, 13(1), 9-20. doi:http://dx.doi.org/10.1016/j.trf.2009.09.004

World Health Organization. (2007). A 5-year WHO strategy for road traffic injury prevention. Retrieved from http://www.who.int/violence_injury_prevention/publications/road_traffic/5yearstrat/en/index.html

Worley, H. (2006). Road Traffic Accidents Increase Dramatically Worldwide. http://www.prb.org/Articles/2006/RoadTrafficAccidentsIncreaseDramaticallyWorldwide.aspx

Zhou, R., Wu, C., Patrick Rau, P.-L., \& Zhang, W. (2009). Young driving learners' intention to use a handheld or hands-free mobile phone when driving. Transportation Research Part F: Traffic Psychology and Behaviour, 12(3), 208-217. doi:http://dx.doi.org/10.1016/j.trf.2008.11.003 